\title{
THE HEART IN CHRONIC MALNUTRITION
}

BY

\author{
J. HIGGINSON, A. D. GILLANDERS, AND J. F. MURRAY
}

From the Baragwanath Non-European Hospital and South African Institute for Medical Research, Johannesburg, South Africa

Received August 26, 1951

A common form of heart disease in the adult Bantu population that is served by this hospital is, we believe, based on chronic malnutrition. It forms a well defined clinical syndrome that has already been described in some detail (Gillanders, 1951). Briefly, patients with heart disease of this kind have a poor nutritional background and characteristically suffer from recurrent attacks of congestive failure. Radiologically, the heart is enlarged, in most instances grossly so, and its range of pulsation is disproportionately small. The enlargement affects all chambers. Dynamically, the circulation is hypokinetic. In the presence of heart failure, the cardiac output is usually between 1 and 2 litres a minute and the stroke volume is correspondingly small. A detailed study of the hæmodynamics will be separately reported.

In the first attack of congestive failure, clinical recovery accrues from a good general diet, but not from thiamin in the absence of such a diet. In proportion to the number of relapses, the heart size fails to revert to normal and recovery from failure becomes less perfect, until, eventually, the syndrome of congestive failure associated with massive enlargement of the heart and extreme œdema becomes refractory to all forms of treatment. Apart from the inevitably fatal outcome of this state, the convalescent patient whose progress is apparently favourable frequently dies unexpectedly and with remarkable suddenness. This may be an expression of the deranged and unstable metabolism that we know exists in these patients and is most readily studied in their carbohydrate utilization. There is no evidence of a genetic transmission of this disease.

The following account of the pathological findings characteristic of nutritional heart disease is based on post-mortem examinations in twelve representative cases, whose salient clinical features are listed in Table I. At the time of death all had some degree of congestive failure.

\section{POST-MORTEM FINDINGS}

On external examination the patients appeared of good physique, without skeletal deformity or signs of specific nutrient deficiencies. Subcutaneous odema of varying degree existed in all. The skin over the extremities was in most cases mildly hyperpigmented and hyperkeratotic. The corresponding histological changes were limited to a minor increase in melanin pigment and slight epithelial hyperkeratosis with or without fibrosis of the corium. No abnormal pigments were observed.

Serous cavities. Ascites was invariable and fibrous adhesions were common around the liver and spleen. In one case the pleural cavities were normal, but in the rest they were either obliterated by œdematous fibrous tissue or contained small effusions. The pericardia contained 25-100 ml. of serous fluid and were otherwise healthy.

Heart. The heart was enlarged in every subject, all chambers being dilated and hypertrophied (Fig. 1). Both sides of the heart were equally involved in all but one case in which there was greater dilatation of the right side. The weight of the hearts and the percentage ratio to total body weight are listed in Table I. 
HIGGINSON, GILLANDERS, AND MURRAY

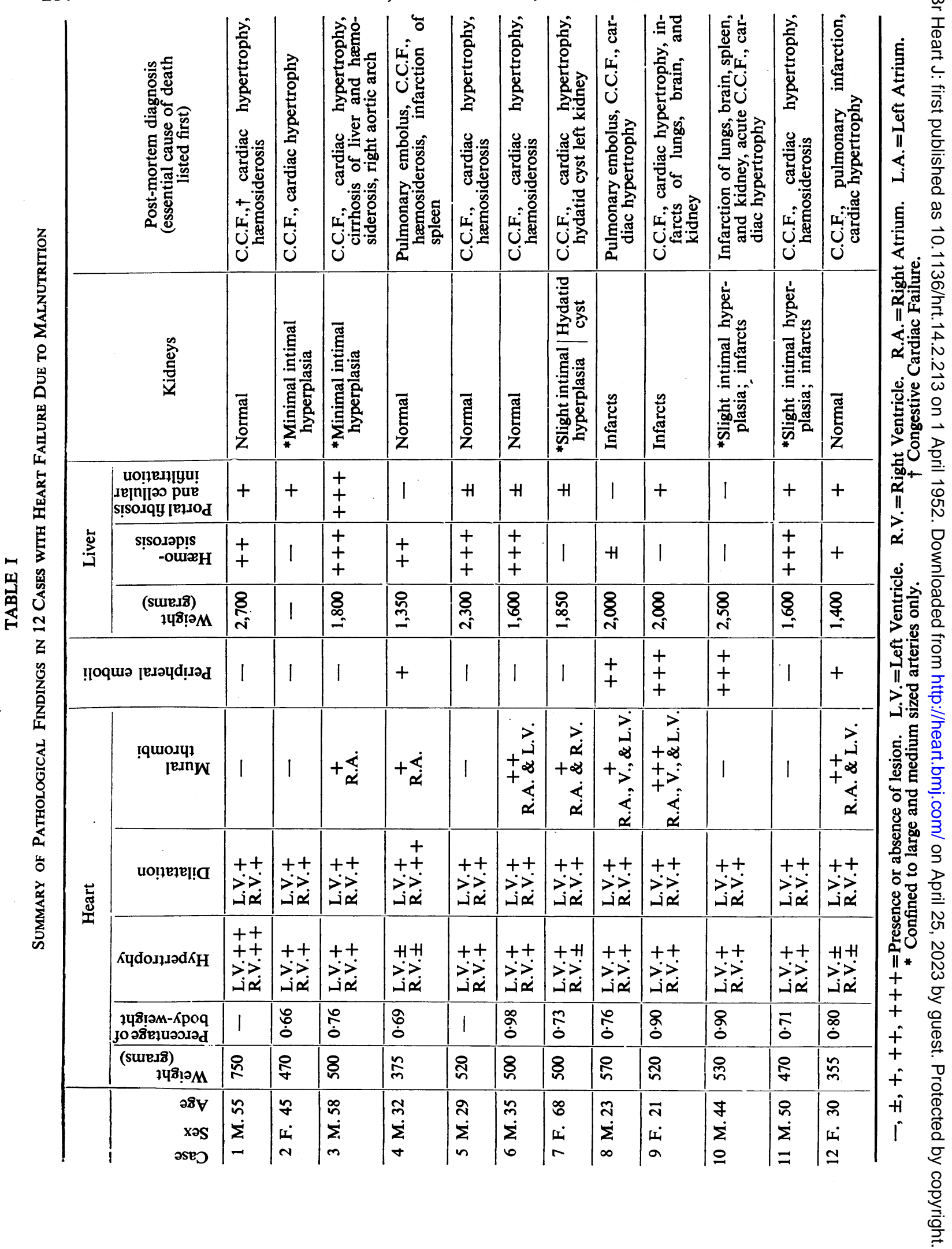




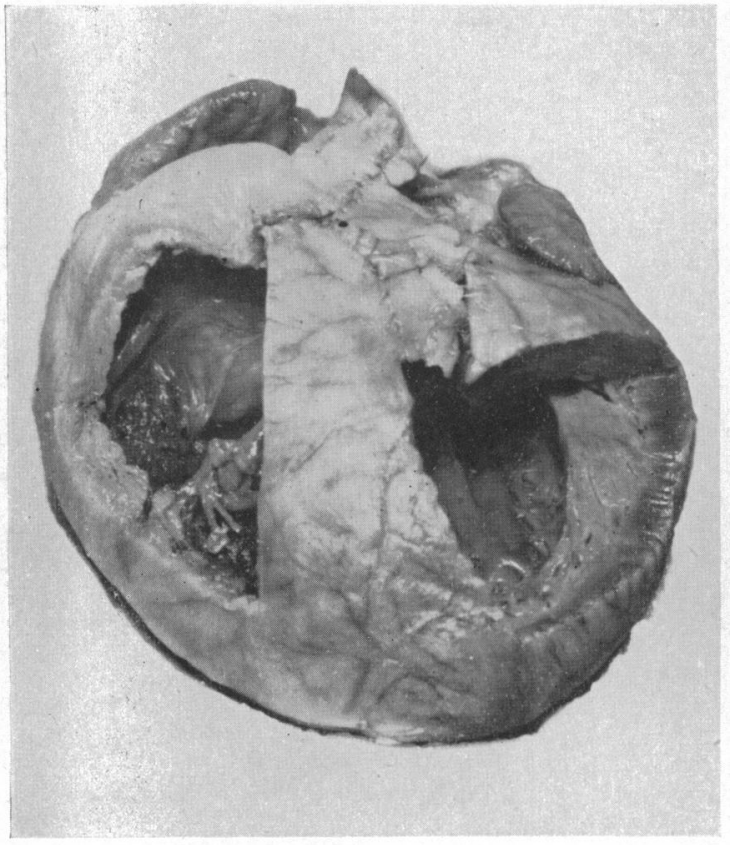

FIG. 1.-The typical generalized dilatation and hypertrophy of the heart found in these patients. Case 8. $\times 1 / 2$.

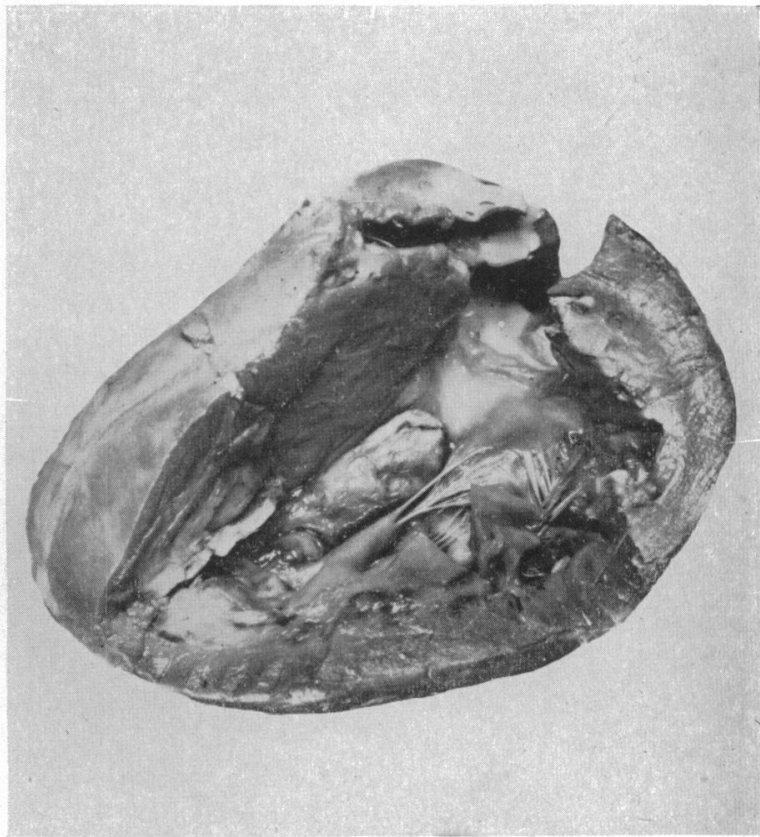

Fig. 2.-The left ventricle has been opened to demonstrate mural thrombi adherent to the endocardium over the septum and apex. Case 9.

Ventricular thrombi adherent to the apical or inferior mural endocardium were found in five patients (Table I); these were recent and confined to the interstices of the trabeculæ carneæ. The underlying myocardium was not recognizably abnormal. In two cases, however (9 and 12), conspicuously larger thrombi measuring up to $4 \mathrm{~cm}$. in diameter coexisted (Fig. 2); these were pale and firmly adherent to the trabecular and mural endocardium whence fibrous bands permeated the superficial layers of the myocardium underneath. Fibrosis of this kind was confined to the immediate neighbourhood of the endocavitory thrombi. Thrombi were also present in the atrial appendages in 7 of the 12 cases.

No significant lesions were found in the valves or cusps. The coronary arteries were invariably patent. In a few of the older patients minimal atheroma was observed, but in no instance did this significantly encroach on the lumen. Petechial hæmorrhages were noted in the epicardial tissues in a quarter of the cases. In one patient (Case 3) there was a right-sided aortic arch with leftsided descent.

On microscopic examination the myocardium showed hypertrophy of the muscle fibres which contained large irregular hyperchromatic nuclei, this change being more marked in the ventricles than in the atria. In several cases there was "intra-cellular odema," especially in the subendocardial, region sometimes giving the muscle fibres a "moth-eaten" appearance. No hydropic degeneration or loss of cross striation was observed. (The terms " intra-cellular cedema" and "hydropic degeneration" often appear to be used as if they were interchangeable. The former expression is used here to imply odema of the muscle cell, revealed by considerable separation of the myofibrils; this is a non-specific change observed in many types of heart failure. The latter is confined to vacuolation of the muscle fibres with droplet formation, the vacuoles not reacting to stains for fat and glycogen.) A moderate degree of interstitial œdema was found in many cases. In nine hearts a fine, poorly staining interstitial fibrosis was noted in the ventricular myocardium (Fig. 3). This was patchy in distribution, frequently perivascular, and tended to be most obvious 


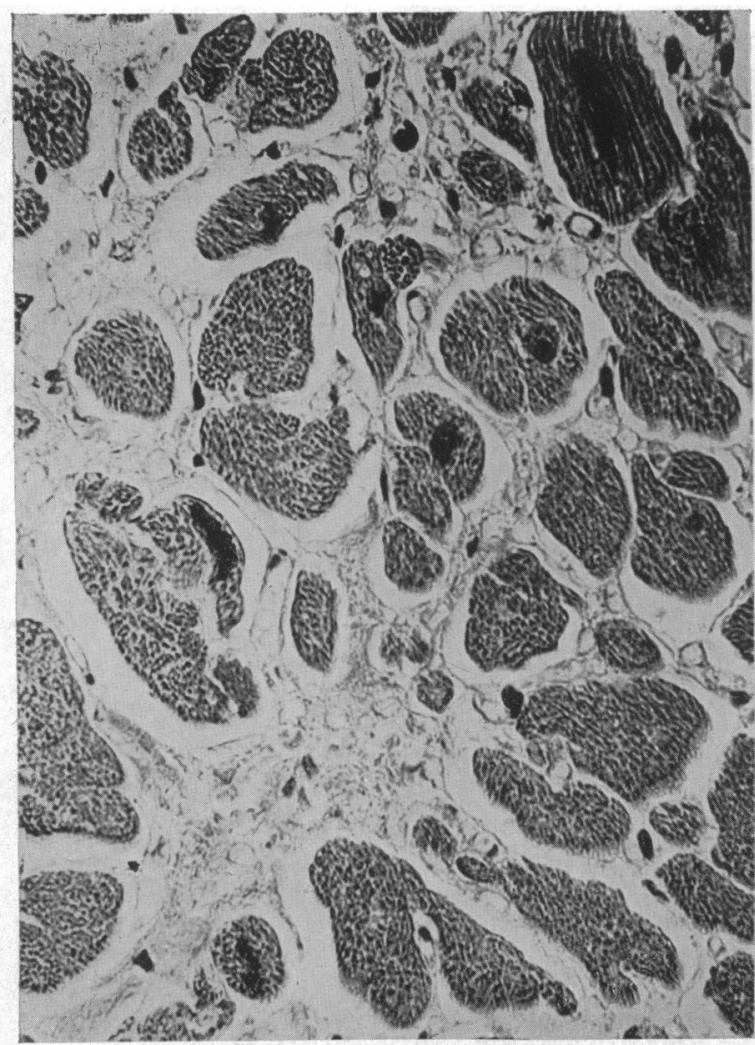

Fig. 3.-This section shows poorly formed odematous collagen fibres extending between the muscle cells, many of which have large hyperchromatic nuclei. H. and E.: $\times 375$.

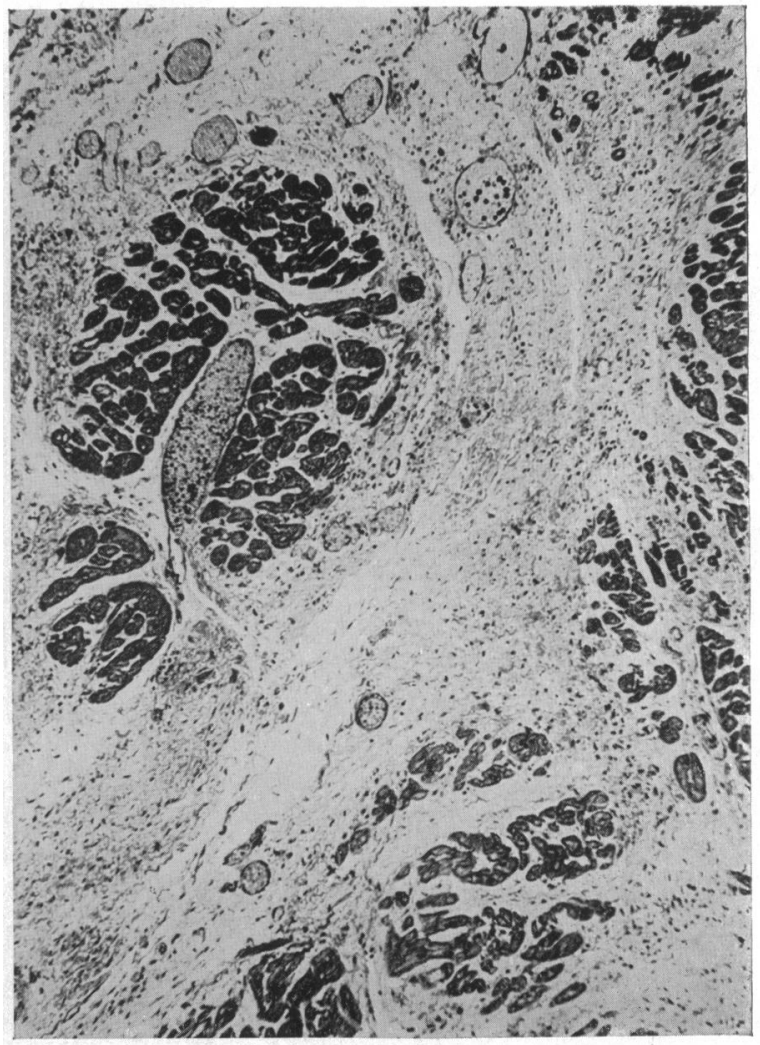

Fig. 4.-Focus of myocardial fibrosis in left ventricle. Case 9. Masson: $\times 66$.

in the subendocardial region. Myocardial lesions were more advanced in four patients (Cases 2, 6,9 , and 12) where areas of fibrous scarring measuring up to $2 \mathrm{sq}$. $\mathrm{mm}$., associated with complete loss of muscle, were found (Fig. 4). Small foci of lymphocytes, polymorphs, and mononuclear cells were also observed diffusely infiltrating between the muscle fibres in Cases 2 and 11 (Fig. 5). In one patient only (Case 11) was fatty degeneration of the myocardium observed and that was of minor degree.

In four of seven cases where the atria were examined in detail, minute areas of focal fibrosis were observed. This was usually of the fine interstitial type, but in two cases it was more pronounced (Fig. 6).

The ventricular thrombi were organized to a varying degree. Some were recent and adhered to the endocardium in only a few areas where early invasion by young fibroblasts and capillaries was beginning (Fig. 7). The deeper parts of others were completely organized and showed foci of old hæmorrhage and infiltration by lymphocytes, plasma, and mononuclear cells. These thrombi were firmly attached to the endocardium (Fig. 8). The underlying myocardium, however, was essentially normal except for the focal scarring and interstitial fibrosis referred to above. No evidence of myocardial infarction was found. In two (Cases 9 and 12) the changes in some thrombi were more advanced and had obscured their relationship to the endocardium. The thrombi showed dense fibrosis, with hyaline change in parts, and merged with the endocardium, whence thick bands of fibrosis penetrated the underlying myocardium. Between the fibrous 


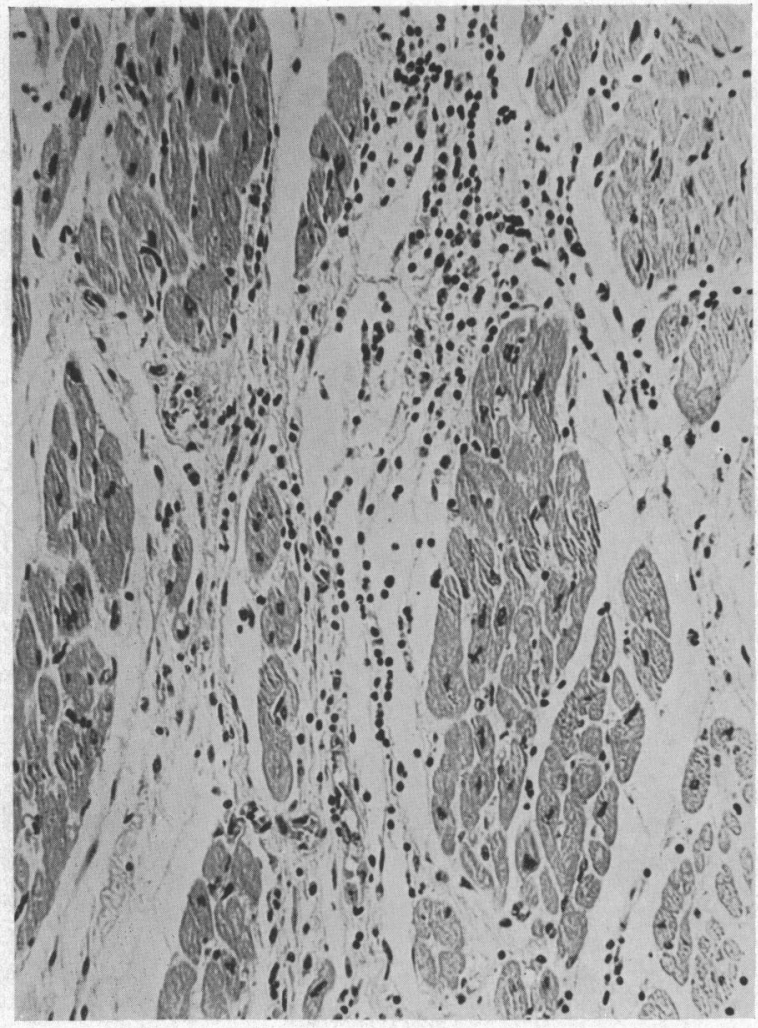

Fig. 5.-Small focus of interstitial lymphocytic and mononuclear cell infiltration in right ventricle. Case 2. H. and E.: $\times 132$.

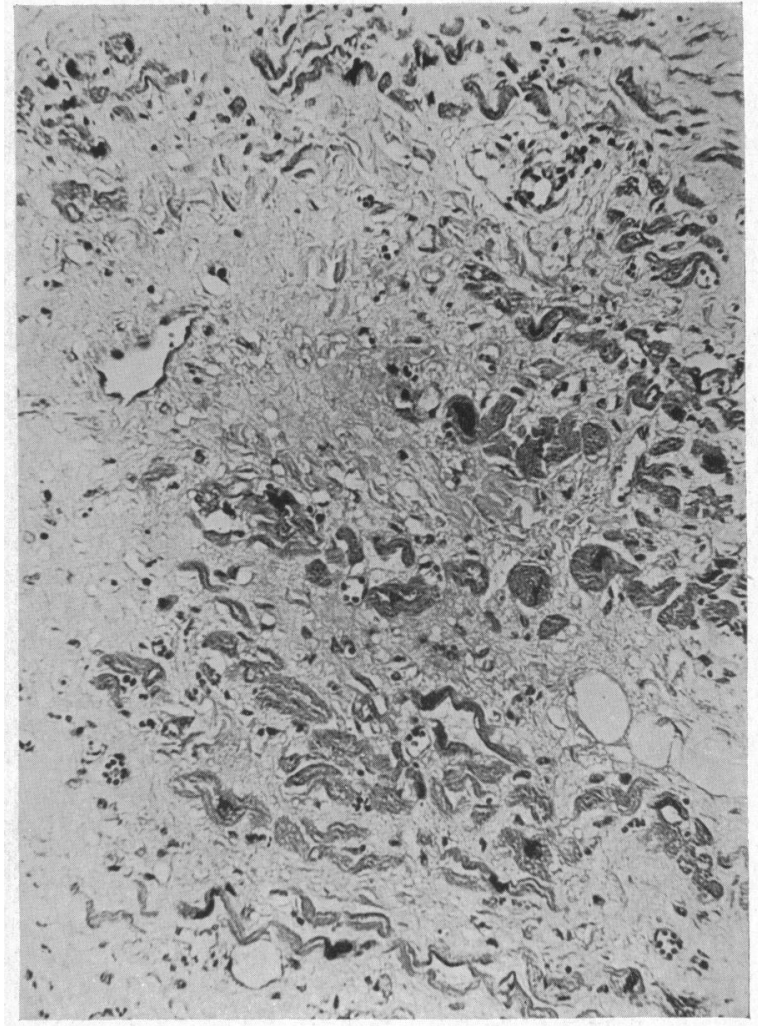

FIG. 6.-Area of fibrous scarring in right atrium. Case 10. H. and E.: $\times 132$.

bands degenerated myocardial fibres were visible, some apparently derived from the trabeculæ carneæ, others from the endocardial portion of the ventricular wall. The atrial thrombi showed a similar variation in the degree of organization.

In no case was excessive hæmofuchsin present nor could hamosiderin be demonstrated histologically. By Bests' carmine stain glycogen was not excessive in the heart, including two samples of cardiac muscle obtained by special cannula immediately after death. No lesion was found in the region of the conducting bundle apart from "intra-cellular œdema." In no instance were Aschoff nodules or other evidence of rheumatic carditis discovered.

Minimal fibrous hyperplasia of the intima was found in the main branches of the coronary arteries in several cases. This change was not more marked than in otherwise normal hearts which were used as controls. The smaller arteries and arterioles were completely normal.

Femoral veins. In three patients these veins contained ante-mortem thrombi.

Lungs. The lungs of all patients were congested and odematous. Five had pulmonary infarcts of varying age. In two of these, thrombi coexisted in the femoral veins and right atrium. Of the remainder thrombi were found in the heart of two patients and femoral veins of one. Death was due to acute pulmonary embolism in Case 8. On microscopic examination varying degrees of passive venous congestion were observed and the presence of hæmorrhagic infarction was confirmed. In two cases healed tubercles were found in the apices of the lungs and hilar lymph glands. No evidence of bronchiectasis, emphysema, schistosomiasis, or primary pulmonary vascular disease was found in any patient. 


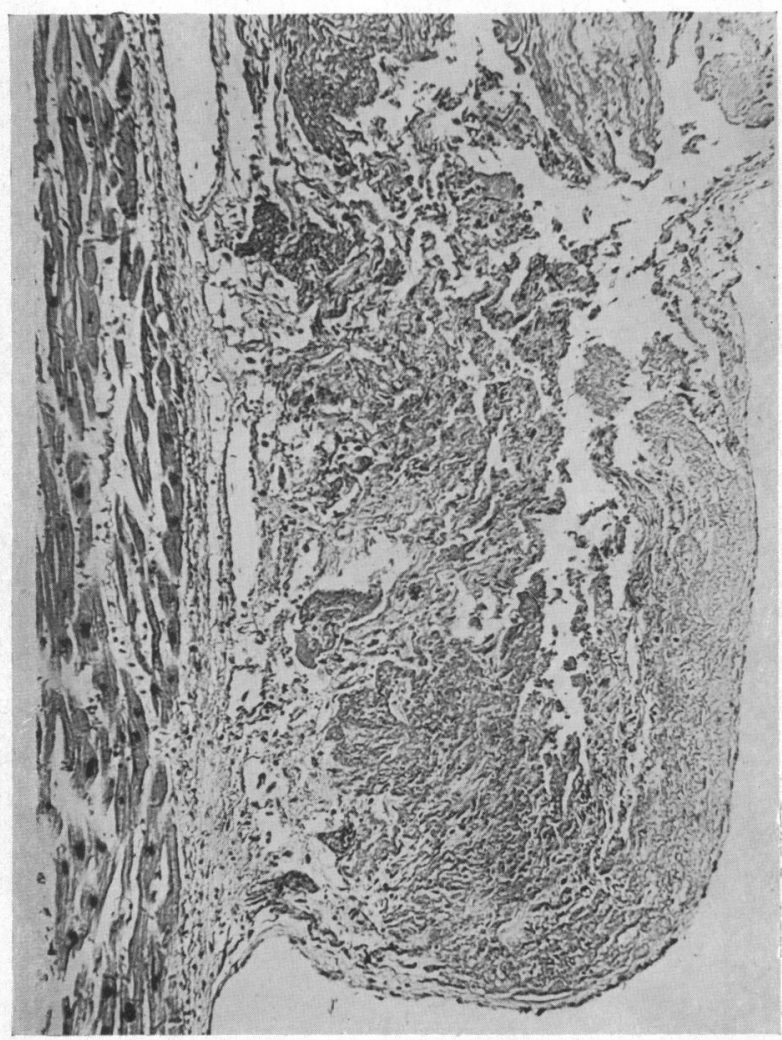

FIG. 7.-Section of recent mural thrombus in ventricle showing early organization. Case 9. H. and E.: $\times 66$.

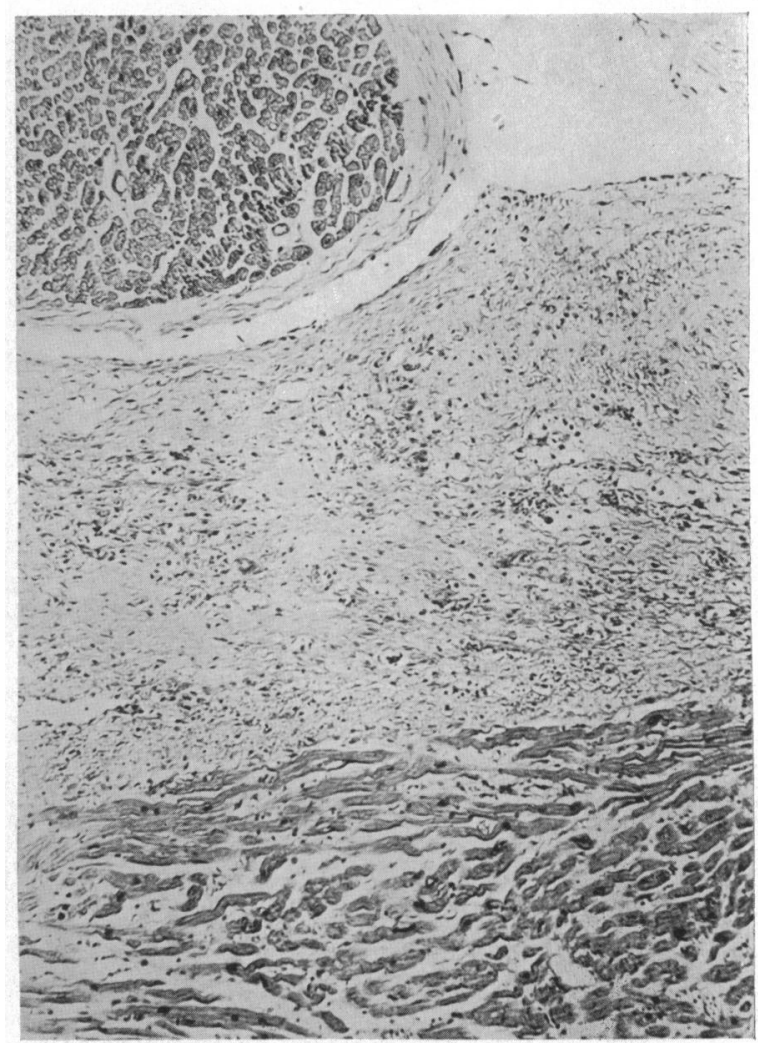

Fig. 8.- Section of organized endocardial thrombus. No significant lesion is present in the underlying myocardium. This photograph demonstrates the position of the thrombus between the interstices of the trabeculæ carneæ. Case 9. H. and E.: $\times 66$.

Liver. The liver was invariably congested and had a nutmeg appearance in those patients who had been in failure for a long time. In seven cases the cut surface had a brown colour and gave a positive Prussian blue reaction. Microscopically, there was passive congestion and distension of the sinusoids in the centre of the lobules associated in some cases with atrophy of the surrounding liver cells and slight fibrosis. In addition there was histological evidence of primary liver disease in all patients but one. The portal tracts showed varying degress of fibrosis, with lymphocytic, mononuclear, and plasma cell infiltration. These changes had advanced to a well developed multilobular cirrhosis in Case 3. In seven of the eight male and in one female case there were hæmosiderin deposits in the parenchymal cells, Kupffer cells, and portal tracts (Fig. 9). There was no apparent correlation between the amount of pigment and the degree of portal fibrosis. Fatty change in the peripheral cells of the lobules was usually absent and when present was minimal.

Spleen. The spleen showed passive venous congestion on gross and microscopic examination. In those cases with hæmosiderosis of the liver it had a rusty brown colour and heavy hæmosiderin deposits were noted in the pulp and occasionally on the fibrous trabeculæ. In Case 4 there was a thrombus in the splenic artery with infarction of the whole organ.

Pancreas. No significant pathological lesions were observed on sections of the pancreas, but a slight interstitial fibrosis was sometimes present and scanty iron deposits were noted in two cases 


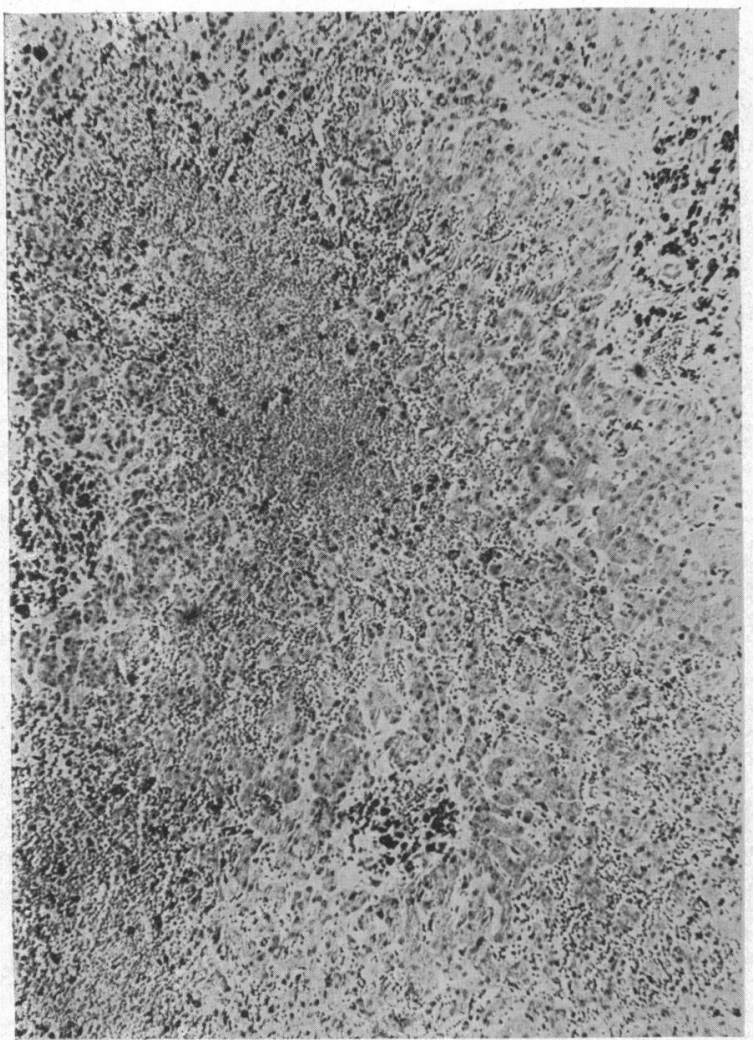

FIG. 9.-Section of liver showing centrilobular passive venous congestion. Hæmosiderin deposits may be observed in the portal tracts. They are also present in the parenchymal cells but cannot be distinguished in this photograph. Case 6 . H. and E.: $\times 66$.

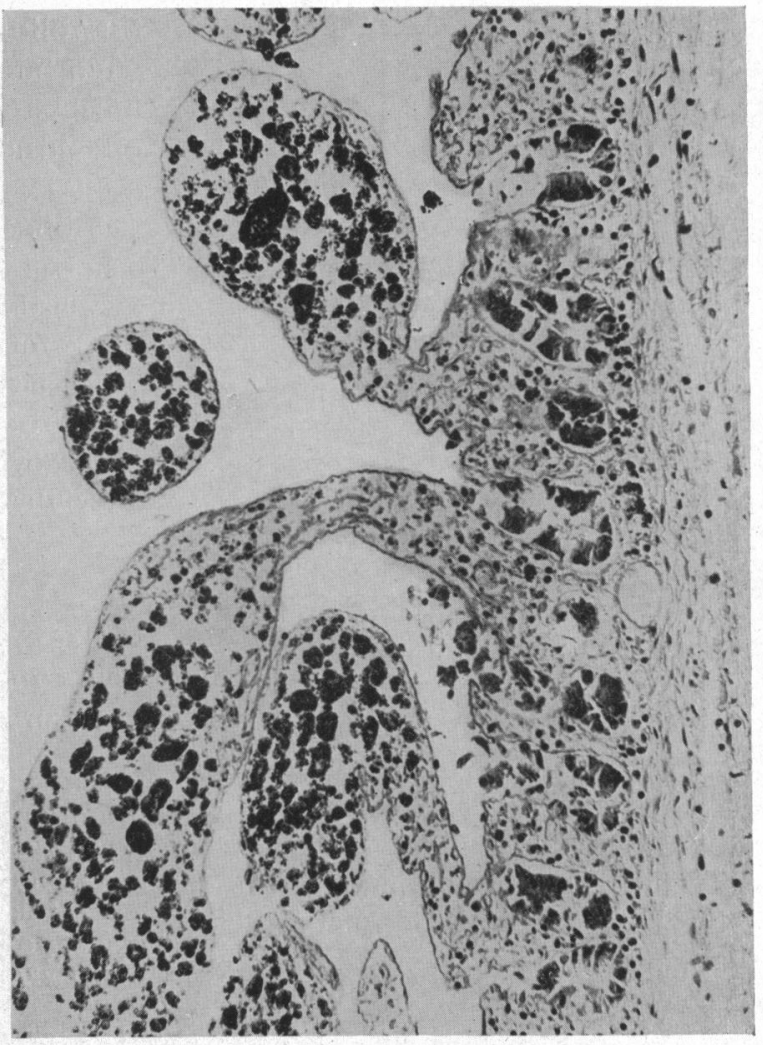

Fig. 10.-Section of jejunum showing very heavy hæmosiderin deposits in the mucosal villi. Case 6. H. and E.: $\times 132$.

with severe generalized hæmosiderosis. In all cases the necropsy was performed too long after death for satisfactory examination of the islet cells.

Suprarenals. These glands were of normal size and showed no abnormality. This was confirmed on section, and in only one case was a slight amount of iron pigment observed in the interstitial tissues. The quantity of lipoids stained by Sudan IV appeared within normal limits.

Kidneys. In all cases the kidneys were congested. On section no lesions were observed in the glomeruli or vessels diagnostic of renal or hypertensive disease, but in some of the older patients slight intimal fibrous hyperplasia was observed in the large and medium sized arteries. In Case 7 there was a hydatid cyst which had a thick fibrous wall and contained several daughter cysts. In four cases there were thrombi in branches of the renal arteries with resultant infarction of the corresponding tissues. The rest of the genito-urinary tract showed no abnormality.

Gastro-intestinal tract. The stomach in all cases appeared normal. In the severely hæmosiderotic cases the duodenal and jejunal mucosa was of a rusty brown colour and gave a strongly positive Prussian blue reaction. This reaction was less intense in the lower portion of the jejunum and was absent in the ileum and large bowel. On microscopic section of the jejunum numerous iron-laden macrophages could be detected in the substantia propia of the villi (Fig. 10). The salivary glands when examined showed no abnormality.

In the hæmosiderotic cases the retro-peritoneal lymph nodes had a rusty brown colour and showed massive hæmosiderin deposits on section. 
Brain and spinal cord. In two cases ( 9 and 10) infarction of the cerebral cortex was observed. These lesions were the result of peripheral emboli, and no primary lesions were found in the cerebral vessels. In Case 6 a few scattered pericapillary hæmorrhages were present in the cortex, but as no other changes were found apart from severe congestion, these were interpreted as terminal congestive phenomena. The organ in the remaining cases showed only moderate congestion.

No specific pathological lesions were found in the thyroid, pituitary, or testes.

Summary. All cases showed clinical and pathological evidence of heart failure. Post mortem, the heart was dilated and hypertrophied, but marked myocardial changes were absent, except in four cases where some focal fibrous scarring was present. Mural thrombi and peripheral emboli were associated findings. In eight cases generalized hæmosiderin deposits were present.

\section{Discussion of Possible Causes that are Excluded}

All these patients had some degree of cardiac failure when they died, but neither the clinical nor pathological findings permitted their inclusion in one of the established groups of heart disease. In making a diagnosis in an anatomical sense the necropsy material was critically examined for all lesions thought to be capable of causing heart failure. The salient facts concerning the most relevant will now be discussed.

Coronary artery disease. In most cases no significant lesion was found in the coronary arteries, but in a minority there was minimal hyperplasia of the intima that did not encroach on the lumen. Thrombosis, severe atheroma, and arteriosclerosis were absent, and cannot therefore have caused this heart failure. Coronary artery disease is excessively rare in the Bantu, and Becker (1945) was able to report only one case of myocardial infarction in a pure Bantu in over three thousand consecutive necropsies on Coloured and Bantu subjects. We ourselves have seen only two cases of coronary thrombosis in over three hundred necropsies in Bantu patients dying of cardiovascular disease, and the clinical diagnosis of ischæmic heart disease was only tenable in two others. The mural thrombi that we have described were superficial and not secondary to underlying myocardial necrosis.

Renal disease and essential hypertension. As stated previously (Gillanders, 1951) a raised arterial blood pressure was not unusual when the patient was in congestive failure but returned to normal level with clinical improvement. In no case were significant histological renal lesions observed. In the older patients minimal vascular changes were found, which were not diagnostic of former hypertension but were consistent with increasing age. Bell (1950) found similar lesions in 90 per cent of kidneys of patients with normal blood pressure dying in the fifth decade. Nor do we regard the hydatid cyst from Case 7 important in this respect, as the patient was not hypertensive in life. Classical concentric hypertrophy of the left ventricle was never observed. Although hypertrophy of the right ventricle occurs in prolonged left ventricular failure, in our series dilatation and hypertrophy of this ventricle appeared to occur concomitantly with that of the left. This was so by both clinical and pathological criteria.

Rheumatic carditis and other valvular diseases. No evidence of rheumatic carditis or other valvular lesions was found by gross and microscopic examination.

Chronic lung disease. The morbid anatomical appearance of the heart was not that of cor pulmonale. Apart from the minor healed tuberculous lesions observed, no other evidence of primary lung disease was found. There was no sternal depression nor other thoracic deformity. The pulmonary vascular system was intact and evidence of schistosomiasis was absent.

Syphilis. The serological tests for syphilis were negative and no sign of this disease was found either clinically or at necropsy.

Glycogen storage disease. Most patients showed abnormalities of carbohydrate metabolism reminiscent of Von Gierke's disease (Gillanders, 1951). In no case, however, did the histological 
findings simulate this disease and abnormal glycogen storage was absent from heart muscle and liver cells. Further excessive glycogen storage is essentially a disease of infancy or childhood.

Anamia, polycythamia, thyrotoxicosis, amyloidosis, and congenital defects were never found, nor other evidence of upper respiratory or other undetermined viral, bacterial, or protozoal infection.

Hamosiderosis and hamochromatosis. Sheldon (1935) reported that, where the heart had been examined, 90 per cent of cases of classical hæmochromatosis showed hæmosiderin in the myocardium and an excess of hæmofuchsin as well. Further, although only rare cases of heart failure attributed to hæmochromatosis have been described, iron deposits in these hearts were considerable (Horns, 1949; Griffin et al., 1950). In none of our cases was iron demonstrable in the myocardium and the quantity of hæmofuchsin was normal, although there were massive deposits of hæmosiderin in the abdominal organs of seven patients.

Generalized hæmosiderosis may be classified as idiopathic, nutritional, hæmolytic or due to excessive parenteral administration of iron (Finch et al., 1950). The hæmosiderosis of the South African Bantu is believed to be of the nutritional type (Gillman et al., 1945). It has been shown experimentally in rats that an unbalanced diet of maize grits and excessive ferrous citrate is followed by iron deposits in the tissues (Kinney et al., 1949). That diet may also be responsible for excessive iron deposition in man is suggested by reports of hæmochromatosis occurring in malnourished German prisoners of war from Russia (Kalk, 1950). Walker and Arvidsson (1950) have shown that considerable iron is available in the diet of the Johannesburg Bantu. In 100 consecutive liver biopsies from patients at this hospital (56 male and 44 female) with the stigmata of chronic malnutrition, 77 per cent of males and 41 per cent of females showed varying degrees of hæmosiderosis; in 44 cases of this type of heart failure the proportions were similar. Accordingly we do not believe that hæmosiderosis is per se the cause of heart failure in these patients.

Isolated myocarditis. It is unlikely that the disease referred to as Fiedler's or isolated myocarditis is a specific entity, as the reported clinical and pathological findings vary greatly. Cellular infiltration and necrosis of the myocardium have been emphasized by several authors (Karsner, 1942; Saphir, 1942). Others have described fibrous scarring of the myocardium with little or no cellular infiltration (Smith and Furth, 1943; Biggart, 1950). Smith and Furth discuss the papers on this subject and suggest that the cases described by them are based on a nutritional deficiency. In reported cases of isolated myocarditis, all gradations in the histological picture are described, even in the one heart, from severe muscle necrosis and cellular infiltration to slight fibrosis. In our patients, however, we found significant scarring in only four cases and minor cellular infiltration in two. In the remainder muscle necrosis and scarring were not a feature and fibrosis was of a fine interstitial type.

Biggart (1950) believes that the primary lesion in isolated myocarditis is muscle necrosis, the products of degeneration giving rise to the infiltrate. If this is true, it is possible that when muscle changes are not severe and there is no myocardial degeneration, cellular infiltration may be absent. Unfortunately we are often unable to demonstrate myocardial damage by histological methods in heart disease of other ætiology even where such damage must exist by accepted standards. We see, however, no advantage in applying either of the terms isolated myocarditis or idiopathic cardiac hypertrophy (Levy and Glahn, 1944), although the present series have some pathological features in common with many cases reported as such.

Beri-beri heart disease. The view prevails that thiamin deficiency may be the cause of cardiovascular dysfunction in man, and cases where this is proven to be so may accurately be referred to as examples of beri-beri heart disease. But on examination of the reported cases the clinical features are clearly variable, as is also the therapeutic response to thiamin (Wenckebach, 1928; Weiss and Wilkins, 1936 and 1937; Kuo, 1939; Dock, 1940; Smith and Furth, 1943; Blankenhorn, 1945; and Alleman and Stollerman, 1948).

The pathology of beri-beri heart disease has been discussed by Aalsmeer and Wenckebach (1929), Wenckebach (1934), Vedder (1938), Weiss (1940), and several of the above authors. The earlier 
authors stressed the degree of right ventricular failure and the dominant dilatation of the right heart; histologically their emphasis was on hydropic degeneration of the myocardium. Weiss and Wilkins (1937) found both right and left heart failure in their cases; they further remarked that hydropic degeneration and intra-cellular odema of the myocardium were not histological findings specific to beri-beri but may be found in heart failure from other causes. This also has been our experience. That myocardial hypertrophy may occur in beri-beri heart disease has been stated by Weiss (1940).

The experimental results of thiamin deficiency in animals are varied, and Wintrobe (1945) stated that the cardiac pathology induced in pigs does not correspond to that described in man. Nor apparently does the human lesion correspond to that described in other animals (Ashburn and Lowry, 1944; Pecora et al., 1950). It is of interest that Follis (1942) was able to prevent the myocardial necrosis caused by a potassium deficiency in rats, by a diet with a low thiamin content.

It is obvious, therefore, that the exact nature of " beri-beri " heart disease in man is obscure, some authors describing a clear-cut clinical picture with a good response to thiamin, others using wider diagnostic criteria and reporting no therapeutic effect of thiamin. Nor are morbid anatomical findings any more specific.

\section{Discussion of Chronic Malnutrition as the Cause}

It has been established that the ætiological background in this form of heart disease is chronic malnutrition (Gillanders, 1951). The post-mortem findings are in accord with this conclusion.

The natural diet of these patients is qualitatively inadequate: it is lacking in animal protein and is unbalanced in amino acids, and its carbohydrate content is disproportionately large and contributes the greatest part of its calorific value. The imperfection of the diet is not reducible to a single nutrient, nor have we been able to establish that deficiency of any single food factor is the cause of this syndrome. Clinically all patients had parenchymal liver disease by existing criteria. Histological liver damage was lacking in only one of the present series and in only 5 of the 44 cases examined by liver biopsy and referred to previously: these liver changes were of a type believed by Gillman and Gillman (1951) to be a result of chronic malnutrition. We do not, however, believe that current histological methods adequately reflect physiological dysfunction. Moreover, even where clinical recovery from heart failure is complete, hepatic dysfunction persists and biopsy reveals no histological retrogression in the primary liver disease. The part, however, played by the liver in the metabolism of the heart and its role in the genesis of this syndrome is problematical.

Although the lesions of chronic malnutrition and dietetic deficiency have been extensively studied in the liver, little is known about their effects on the cardiovascular system with the exception of thiamin and potassium lack in animals. Acute and subacute starvation are known, however, to cause atrophy of the myocardium in common with other organs. We conclude that æatiological malnutrition, in so far as the heart and circulation are concerned, must be of long duration (Gillanders, 1951). We also believe that although subnutrition is a dominant ætiological influence other (perhaps positive) environmental circumstances may contribute to the end result.

In some patients, apart from hypertrophy the pathological changes in the myocardium were slight and non-specific. The fine interstitial fibrosis observed was of a patchy distribution, and possibly the result of interstitial œdema and chronic heart failure. In the four patients, however, where scarring was more obvious, the histological features were those of focal muscle necrosis and degeneration with replacement fibrosis. In Cases 9 and 12 the myocardial fibrosis in the region of the thrombi was interpreted as secondary to organization of the thrombi and not their cause. The severe and widespread sub-endocardial fibrosis in non-hypertrophied hearts described by Davies (1948) in patients from Central Africa was never observed.

Although the primary stimulus to cardiac hypertrophy is unknown, the association of hypertrophy with other changes in the heart are sufficiently constant to imply a causal relationship. 
It has been demonstrated experimentally by Eyster (1928) that hypertrophy follows cardiac dilatation, and Harrison and Wood (1949) have shown that cardiac hypertrophy in ischæmic heart disease is a function of the duration of congestive failure. Both these hypotheses may be the expression of a single cause. In our patients we incline to the view that cardiac hypertrophy is a reflection of chronic heart failure. The difficulty, however, in obtaining from these patients accurate records of the duration of symptoms precludes us from attempting to correlate these with the heart weight.

The origin of the mural thrombi is obscure and we are not entirely satisfied that present-day concepts adequately explain their formation. It may be that changes in the blood flow with consequent eddying may be largely responsible.

It is clear that while as yet no specific histological lesions can be ascribed to this syndrome, a characteristic pattern is observed post mortem. The pathological diagnosis should be considered in this country in those cases where there is evidence of congestive failure in association with cardiac enlargement, visceral infarction, and liver damage, but without the commonly accepted causes of cardiac failure.

\section{SUMmaRY}

The urbanized South African Bantu suffers from a form of heart disease that we believe is based on chronic malnutrition.

The pathological features in a representative group of 12 fatal cases of this kind are described. Although no specific histological lesions were found a distinctive pathological pattern was recognizable. In all cases the hearts were dilated and hypertrophied. Other myocardial lesions were inconspicuous, except that in four cases minute foci of fibrous scarring were found. Endocardial mural thrombi were observed in approximately half the patients and peripheral emboli were equally frequent. In all cases but one primary liver injury was demonstrated histologically and in twothirds hæmosiderin deposits were widespread.

The morbid anatomical findings are discussed with reference to the ætiological diagnosis.

We are indebted to Mr. F. A. Brandt of the South African Institute for Medical Research for the photographs in this paper, and to those house-physicians who assisted in the collection of clinical data.

\section{REFERENCES}

Aalsmeer, W. C., and Wenckebach, K. F. (1929). Wien. Arch. intern. Med., 16, 193.

Alleman, R. J., and Stollerman, G. H. (1948). Ann. intern. Med., 28, 949.

Ashburn, L. L., and Lowry, J. V. (1944). Arch. Path., 37, 27.

Becker, B. J. P. (1946). S. Afr. J. med. Sci., 11, 97.

Bell, E. T. (1950). Renal Diseases. 2nd ed., Lea and Febiger, Philadelphia.

Biggart, J. H. (1950). Ulster med. J., 19, 59.

Blankenhorn, M. A. (1945). Ann. intern. Med., 23, 398.

Davies, J. N. P. (1948). E. Afr. med. J., 25, 10.

Dock, W. (1940). Trans. Ass. Amer. Phys., 55, 61.

Eyster, J. A. E. (1928). J. Amer. med. Ass., 91, 1881.

Finch, C. A., Hegsted, M., Kinney, T. D., Thomas, E. D., Rath, C. E., Haskins, D., Finch, S., and Fluharty, R. G. (1950). Blood, 5, 983.

Follis, R. H. (1942). Bull. Johns Hopk. Hosp., 71, 235.

Gillanders, A. D. (1951). Brit. Heart J., 13, 177.

Gillman, J., and Gillman, T. (1951). Perspectives in Human Malnutrition. Grune and Stratton, New York.

Gillman, J., Mandelstam, J., and Gillman, T. (1945). S. Afr. J. med. Sci., 10, 109.

Griffin, W. R., Nelson, H. G., and Seale, J. R. (1950). Amer. Heart J., 39, 904.

Harrison, C. V., and Wood, P. C. (1949). Brit. Heart J., 11, 205.

Horns, H. L. (1949). Amer. J. Med., 6, 272.

Kalk, H. (1950). Dtsch. med. Wschr., 75, 225.

Karsner, H. T. (1942). Human Pathology. 6th ed., Lippincott, Philadelphia.

Kinney, T. D., Hegsted, D. M., and Finch, C. A. (1949). J. exp. Med., 90, 137.

Kuo, P. T. (1939). Chin. med. J., 55, 427. 
Levy, R. L., and von Glahn, W. C. (1944). Amer. Heart J., $28,714$.

Pecora, L. J., Ashburn, L. L., and Hundley, J. M. (1950). Proc. Soc. exp. Biol., 74, 721.

Saphir, O. (1941). Arch. Path., 32, 1000.

Sheldon, J. H. (1935). Hamochromatosis. Oxford University Press, London.

Smitn, J. J., and Furth, J. (1943). Arch. intern. Med., 71, 602.

Vedder, H. B. (1938). J. Amer. med. Ass., 110, 893.

Walker, A. R. P., and Arvidsson, U. B. (1950). Nature, 166, 438.

Weiss, S. (1940). J. Amer. med. Ass., 115, 832.

-, and Wilkins, R. W. (1936). Trans. Ass. Amer. Phys., 51, 341.

,- , (1937). Ann. intern. Med., 11, 104.

Wenkebach, K.F. (1928). Lancet, 2, 265.

-, (1934). Das Beri-Hertz, Julius Springer, Berlin.

Wintrobe, M. M. (1945). Arch. intern. Med., 76, 341. 